\title{
Separation and Recovery of Nickel and Copper from Multi-Metal Electroplating Sludge by Co-Extracting and Selective Stripping
}

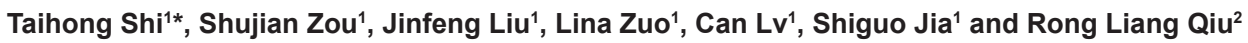

${ }^{1}$ School of Environmental Science and Engineering, Sun Yat-Sen University, Guangzhou 510275, P.R. China

${ }^{2}$ Guangdong Provincial Key Laboratory of Environmental Pollution Control and Remediation Technology, Guangzhou 510275, P.R. China

\begin{abstract}
N902 diluted with kerosene was used to co-extract copper and nickel from the ammoniac-carbonate leaching liquor of multi-metal electroplating sludge. The influence factors of the ammoniac-carbonate leaching and the extracting process on the recovery of copper and nickel were studied. The leaching rate of copper and nickel can reach to $90 \%$ and the other metal ions are less leached under the optimal leaching condition. In order to optimize the extraction condition, the $\mathrm{L}_{9}\left(3^{4}\right)$ intersecting experiment of co-extraction of copper and nickel ions was tested. For a typical ammonium carbonate leaching solution containing $\mathrm{Cu}^{2+} 2.23 \mathrm{~g} / \mathrm{L}, \mathrm{Ni}^{2+} 3.31 \mathrm{~g} / \mathrm{L}, \mathrm{Cr}<0.02 \mathrm{~g} / \mathrm{L}$ and pH 9.0-9.5, the optimal conditions of co-extraction, $\mathrm{NH}_{3}$ escape and selective stripping of nickel and copper were established. The percentage of extraction was more than $97.0 \%$ for both copper and nickel, and the stripping percentages were $99.0 \%$ and $99.3 \%$ for copper and nickel, respectively. This study clearly demonstrates that N902 is suitable for the selective separation and recovery of copper and nickel from the multi-metal electroplating sludge in pure sulfate product as an extractant.
\end{abstract}

Keywords: Co-extraction; Electroplating sludge; Copper and Nickel; Recovery; Selective stripping; N902

\section{Introduction}

Electroplating sludge contains a great number of valuable chromium, nickel and copper. In china, $4 \times 10^{8}$ tons of plating waste water containing heavy metals was generated annually and the content of $\mathrm{Cu}, \mathrm{Ni}$ and $\mathrm{Cr}$ in the amount of sewage amount to 5,000 tons, 4,000 tons and 20,000 tons, respectively [1]. So far, plating sludge and metals in it have been regarded as solid wastes and been disposed by means of landfill site. However, the way to dispose plating sludge leads to serious disadvantages, as it has great effect on the surface of the earth as an environmentally hazardous material. On the other hand, the reuse of heavy metals might bring great potential profits. With the increase in the consumption of various metals in recent years, increasing disquisitions focusing on metals recovery from plating sludge and wastewater have been observed [2-4].

In order to protect the environment and recover the valuable metals, techniques based on physical and chemical mechanisms (such as adsorption, ion exchange, membrane and extracting processes) were used. The recovery of $\mathrm{Cr}$ from electroplating effluent has been reported in our previous work [2]. From an economical point of view, $\mathrm{Cu}$ and $\mathrm{Ni}$ are the most valuable metals value to recycle. As for the recovery of $\mathrm{Cu}$ and $\mathrm{Ni}$ from multi-metal electroplating sludge, the previous investigation focuses on selective chemical precipitation of $\mathrm{Cu}$ and $\mathrm{Ni}$ with $\mathrm{Na}_{2} \mathrm{~S}$ or $\mathrm{NaOH}$ by controlling $\mathrm{pH}$ of solution. Kuchar et al. [3] reported the selective recovery of $\mathrm{Cu}$ and $\mathrm{Ni}$ from a mixed plating sludge by sulfidation treatment. As a result, it was found that the precipitation selectivity was $95.5 \%$ for $\mathrm{Cu}$ as $\mathrm{CuS}$ at $\mathrm{pH}=1.5$ and $94.7 \%$ for $\mathrm{Ni}$ as $\mathrm{NiS}$ at $\mathrm{pH}=6.7 \pm 0.2$. Silva et al. [4] reported a hydrometallurgical treatment involving the solvent extraction and recovery of $\mathrm{Zn}$ and $\mathrm{Ni}$ from a sulfuric acid leach solution of galvanic sludge using di-(2-ethylhexyl) -phosphoric acid ( $\mathrm{D}_{2}$ EHPA) and bis(2,4,4-trime-thylpentyl) phosphoric acid (Cyanex272). The preliminary tests revealed the necessity to remove other metals from the leaching solution prior to solvent extraction, and therefore it comes into being chromium precipitate sludge. Literatures [5-8] reported the series results of the extraction and recovery of $\mathrm{Cu}$ and $\mathrm{Ni}$ from the ammoniac leaching solution obtained from the processing of manganese nodules containing $\mathrm{Cu}, \mathrm{Ni}$ and cobalt, and it was treated for $\mathrm{Cu}-\mathrm{Ni}$ separation using LIX64N as extractant. Ni was selectively recovered from the loaded organic phase through $\mathrm{pH}$ controlled stripping using dilute $\mathrm{H}_{2} \mathrm{SO}_{4}$ solution and $\mathrm{Cu}$ was stripped subsequently with a more concentrated $\mathrm{H}_{2} \mathrm{SO}_{4}$ solution [6].

Rhoads et al. [9] applied the co-extraction and selective stripping process to treat leaching liquor of $\mathrm{Ni}$ laterites. An ammoniac ammonium sulfate solution containing (in $\mathrm{kg} / \mathrm{m}^{3}$ ) $1.00 \mathrm{Ni}, 0.03 \mathrm{Cu}, 0.3$ Co, $0.02 \mathrm{Zn}, 17.8 \mathrm{NH}_{4} \mathrm{OH}$ and $294\left(\mathrm{NH}_{4}\right)_{2} \mathrm{SO}_{4}$ was used to co-extract $\mathrm{Cu}$ and $\mathrm{Ni}$ in three stages with a 12 vol. \% LIX64N extractant. After ammonia washing, $\mathrm{Cu}$ and $\mathrm{Ni}$ were selectively stripped in three stages. Sandhibigraha and Bhaskara Sarma [10] reported that the extraction and stripping from ammoniac carbonate solution and the influence of $\mathrm{pH}$ and extractant concentration on the co-extraction have been studied. For a typical solution containing about $3 \mathrm{~kg} / \mathrm{m}^{3} \mathrm{Cu}$ and $\mathrm{Ni}$ and $60 \mathrm{~kg} / \mathrm{m}^{3}$ of ammonium carbonate, the percentage of extraction was about $100 \%$ for both $\mathrm{Cu}$ and $\mathrm{Ni}$, and the percentages of stripping were about $100 \%$ and $99.2 \%$ for $\mathrm{Cu}$ and $\mathrm{Ni}$, respectively.

As a whole, the chemical processing method of multi-metal electroplating sludge for recovery of valuable metals is difficult because of its multi-step process and environmental issue, and it is economical only under favorable conditions. Up to date extracting technology can be a good choice to treat and utilize multi-metal electroplating sludge for its economically and environmentally suitable way to recover valuable metal elements. Solvent extraction is now a very wellestablished process in hydrometallurgy. It is used for the separation and recovery of $\mathrm{Cu}, \mathrm{Ni}, \mathrm{Co}, \mathrm{Zn}$, rare earths and the platinum group metals etc. In this work, an ammonium leaching solution, which comes

*Corresponding author: Taihong Shi, School of Environmental Science and Engineering, Sun Yat-Sen University, Guangzhou 510275, P.R. China, Tel: 0086020-84115065; Fax: 0086-020-39332690; E-mail: eesshth@mail.sysu.edu.cn

Received November 02, 2011; Accepted December 12, 2011; Published December 14, 2011

Citation: Shi T, Zou S, Liu J, Zuo L, Lv C, et al. (2011) Separation and Recovery of Nickel and Copper from Multi-Metal Electroplating Sludge by Co-Extracting and Selective Stripping. J Civil Environment Engg 1:103. doi:10.4172/2165-784X.1000103

Copyright: () 2011 Shi T, et al. This is an open-access article distributed under the terms of the Creative Commons Attribution License, which permits unrestricted use, distribution, and reproduction in any medium, provided the original author and source are credited. 
from the first stage of two-stage leaching of multi-metal electroplating sludge, was used to recover $\mathrm{Cu}$ and $\mathrm{Ni}$ with co-extracting and selectively stripping technology of more economical and easy operation. A cheap and effective extractant N902 (made in China) was applied. The ammoniac leaching solution mainly containing $\mathrm{Cu}$ and $\mathrm{Ni}$ was obtained from multi-metal electroplating sludge through ammoniac ammonium carbonate leaching to solubilize $\mathrm{Cu}$ and $\mathrm{Ni}$ as their ammine carbonate complexes and reject $\mathrm{Fe}$ and $\mathrm{Cr}$ in the residue. The parameters of extracting process were optimized for the co-extraction of $\mathrm{Ni}$ and $\mathrm{Cu}$, ammonia scrubbing from the loaded organic phase and selective stripping of $\mathrm{Ni}$ and $\mathrm{Cu}$ with sulfuric acid from the ammoniafree organic phase.

\section{Experimental}

\section{Reagents}

A stock solution of $\mathrm{Cu}^{2+}$ and $\mathrm{Ni}^{2+}$ for batch extracting test was prepared by dissolving $\mathrm{NiSO}_{4} \cdot 6 \mathrm{H}_{2} \mathrm{O}$ and $\mathrm{CuSO}_{4} \cdot 5 \mathrm{H}_{2} \mathrm{O}$ (obtained from Guangzhou Chemical Reagent Factory, China) into distilled water and diluting to content volume. N902 (obtained from Yashi Chemical Co. Shanghai, China) was used as an extractant, and kerosene (mostly aliphatic) was used as the diluents to obtain the desired concentration of the extractant. The chemical agents of $\mathrm{NH}_{3} \mathrm{H}_{2} \mathrm{O}, \mathrm{NH}_{4} \mathrm{HCO}_{3}$, $\mathrm{Al}(\mathrm{OH})_{3}, \mathrm{HCl}$ and $\mathrm{H}_{2} \mathrm{SO}_{4}$ were got from the Chemical Reagent Factory, Guangzhou. All the reagents were analytical grade.

\section{Ammonium leaching of electroplating sludge}

A representative sample of $1 \mathrm{~kg}$ multi-metal electroplating sludge (obtained from the Ming Run Electroplating Plant, Guangdong, Foushan City, China) was homogenized after been dried, mixed and sieved ( $\leq 160 \mathrm{mesh}$ ). Chemical analysis of the multi-metal electroplating sludge was determined by ICP (IRIS-HR, U.S.A).

Leaching batch experiment was performed in a $500-\mathrm{mL}$ closed glass container immersed in a thermostatically controlled water bath equipped with mechanical stirrer [1]. The sample was leached with 8 $\mathrm{mol} / \mathrm{L} \mathrm{NH}_{3}$ and $5 \mathrm{~mol} / \mathrm{L} \mathrm{NH}_{4} \mathrm{HCO}_{3}$ at $75^{\circ} \mathrm{C}$ by liquid/solid ratio of $20: 1$ for $3.5 \mathrm{hrs}$. A stirring speed of $800 \mathrm{rpm}$, with a magnetic stirrer, was set up to ensure the full suspension of particles and to improve the liquidto-solid phase contact. The reaction mixture was filtrated and washed with deionized water. The ammonium solubility metal ions (i.e. $\mathrm{Cu}^{2+}$ and $\mathrm{Ni}^{2+}$ ions mainly) were dissolved into the filtrate, and the other metal ions (i.e. $\mathrm{Cr}^{2}$ and $\mathrm{Fe}^{3+}$ ions) were blocked into the residue. Then $\mathrm{Cu}^{2+}$ and $\mathrm{Ni}^{2+}$ ions were separated from the $\mathrm{Cr} / \mathrm{Fe}$ and other impurity ions which may be depressed on the extracting rate of $\mathrm{Cu}^{2+}$ and $\mathrm{Ni}^{2+}$ ions. The concentration of metals in leaching solution was determined by ICP.

Scheme 1 shows the procedures to follow in this work for the leaching of electroplate sludge.

\section{Extracting experimental}

All the experiments were carried out in shake flasks at room temperature $\left(30 \pm 0.5^{\circ} \mathrm{C}\right)$. $\mathrm{N} 902$ was mixed with Kerosene (as the diluent) to obtain the desired concentration of the extractant. The aqueous and organic phases were contacted for the desired time.

UV 751-Vis Spectrophotometer (Precision Scientific Instruments Ltd., Shanghai, China) was used for the measurement of metal ions concentration of $\mathrm{Cu}, \mathrm{Ni}, \mathrm{Cr}, \mathrm{Zn}$ and $\mathrm{Fe}$ in aqueous phase and $\mathrm{pHs}$ 3C meter (Shanghai Precision \& Scientific Instrument Co. Ltd.) for the measurement of the $\mathrm{pH}$. The concentration of $\mathrm{Cu}^{2+}$ and $\mathrm{Ni}^{2+}$ ions in organic phase was calculated by law of conservation of matter.
The computing formula of extraction percentage is as follows:

$$
\mathrm{E}=\frac{\mathrm{C}_{0 .}-\mathrm{C}_{\mathrm{eq}}}{\mathrm{C}_{\mathrm{W}}} \cdot 100 \%
$$

Where $\mathrm{E}$ is the extracting percentage (\%), $\mathrm{C}_{\mathrm{o}}$ for the concentration of metal ion in organic phase $(\mathrm{mg} / \mathrm{L}), \mathrm{C}_{\mathrm{eq}}$ for the concentration of metal ion in aqueous phase $(\mathrm{mg} / \mathrm{L})$ and $\mathrm{C}_{\mathrm{w}}$ is the initial concentration of metal ion $(\mathrm{mg} / \mathrm{L})$.

Ultimately, the stripping metal salt from the organic phase was concentrated by evaporating and crystallizing with the pure product as $\mathrm{NiSO}_{4} \cdot 6 \mathrm{H}_{2} \mathrm{O}$ and $\mathrm{CuSO}_{4} \cdot 5 \mathrm{H}_{2} \mathrm{O}$ forms.

\section{Results and Discussion}

\section{Separation of $\mathrm{Cu}$ and $\mathrm{Ni}$ from other metals}

Physico-chemical characteristic of multi-metal electroplating sludge: The sludge used in this study was got from a $\mathrm{Cu} / \mathrm{Ni} / \mathrm{Cr}$ plating plant in Fushan City, in the south China, which was produced by the physico-chemical treatment of wastewater. This sludge was mostly composed of metal hydroxide gels, sulphate salts and some chlorides, thus it had a relatively complex structure and a reasonable high chemical variability which determined by producing address, time, product

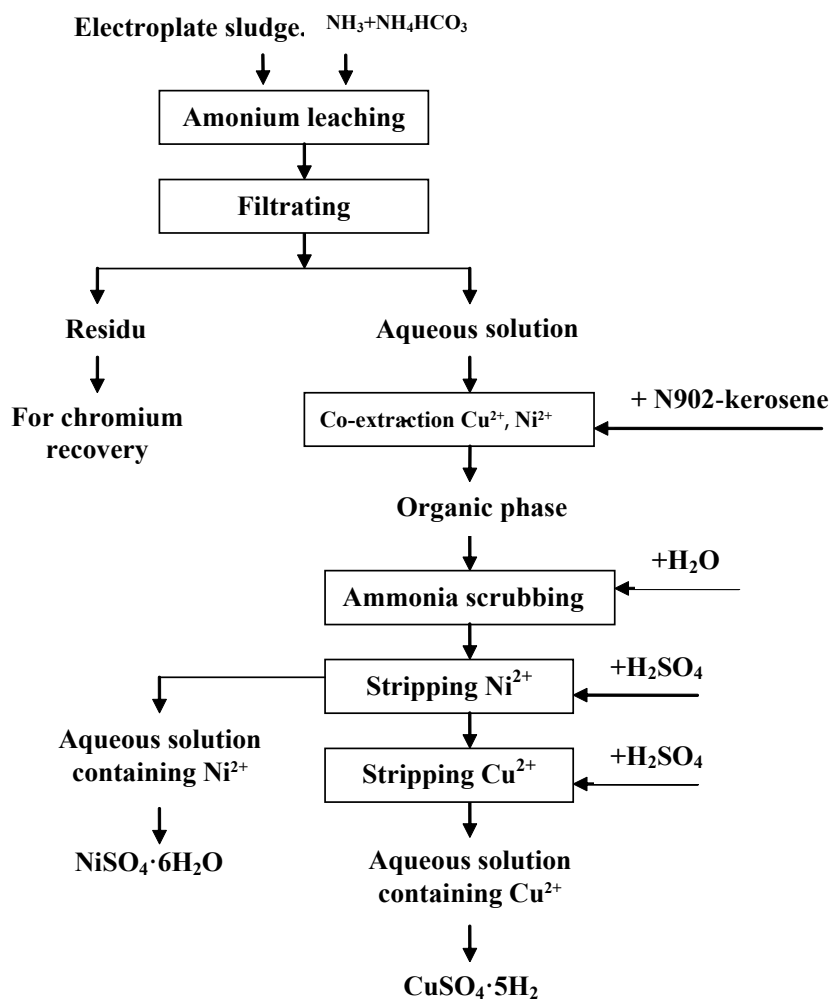

Scheme 1: The process flowsheet followed in this work for the metals recovery from electroplate sludge.

\begin{tabular}{|l|l|l|l|l|l|}
\hline \multicolumn{7}{|c|}{ Density $\left(\mathrm{g} \mathrm{cm}^{-3}\right)$} & $3.41 \mathrm{H}_{2} \mathrm{O}(\%)$ & $61.8 \%$ Blue and black solid \\
\hline Elements in the dried sludge $(\mathrm{wt} . \%)$ \\
\hline $\mathrm{Al}$ & 1.35 & $\mathrm{Fe}$ & 16.64 & $\mathrm{~Pb}$ & 0.21 \\
\hline $\mathrm{Ca}$ & 1.89 & $\mathrm{Ni}$ & 7.08 & $\mathrm{Si}$ & 16.83 \\
\hline $\mathrm{Mg}$ & 1.45 & $\mathrm{Cu}$ & 4.65 & $\mathrm{~K}$ & 0.84 \\
\hline $\mathrm{Cr}$ & 11.16 & $\mathrm{Zn}$ & 2.47 & $\mathrm{~S}$ & 8.26 \\
\hline
\end{tabular}

Table 1: Relevant physical-chemical characteristics of the sludge. 
specifications, processing/operation variations. The main metal species exist in the form of nitro at $105^{\circ} \mathrm{C}$, and then comminuted and sieved. Particles of a size $<160$ mesh were selected. The powdered material was thoroughly homogenized, and the representative samples were taken for chemical characterization and subsequent leaching tests. The chemical composition (major elements) of the sludge was determined by submitting three small representative samples to digestion with aqua regia. The resulting solutions were analyzed by atomic absorption (a)

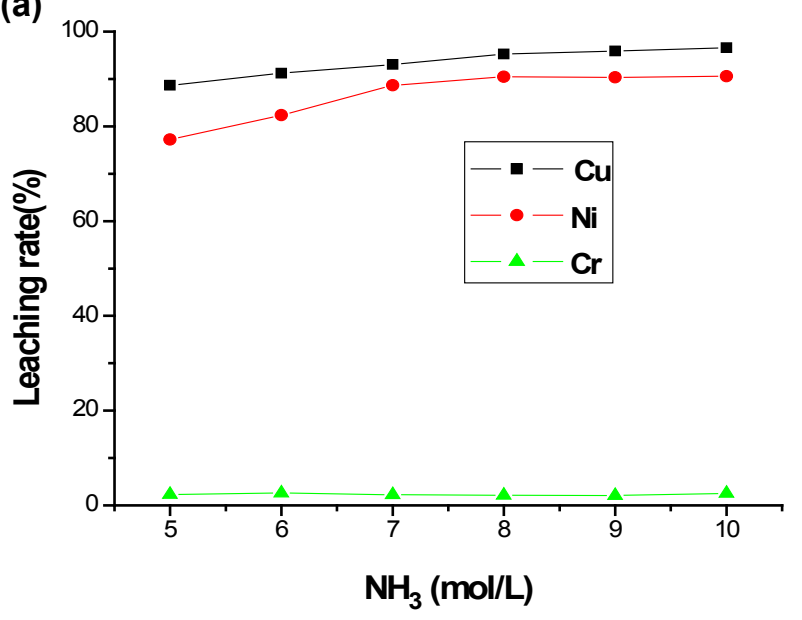

(c)

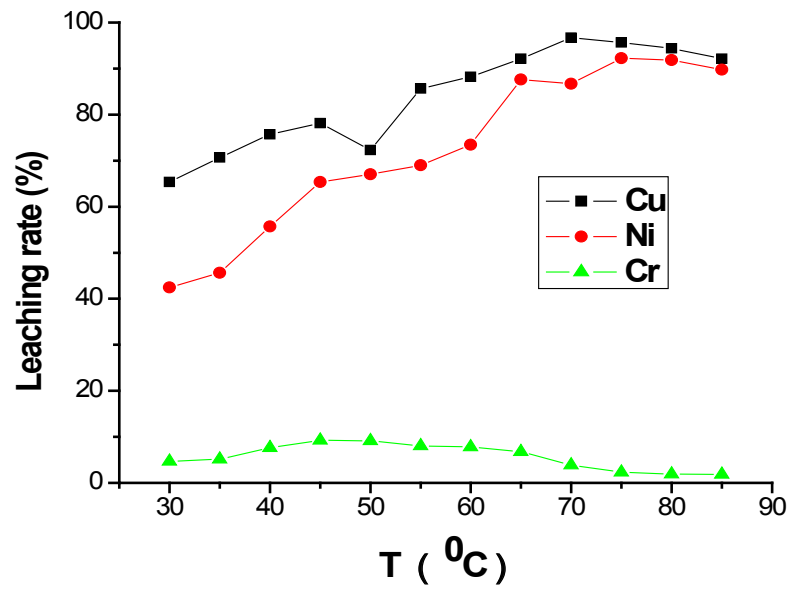

(b)

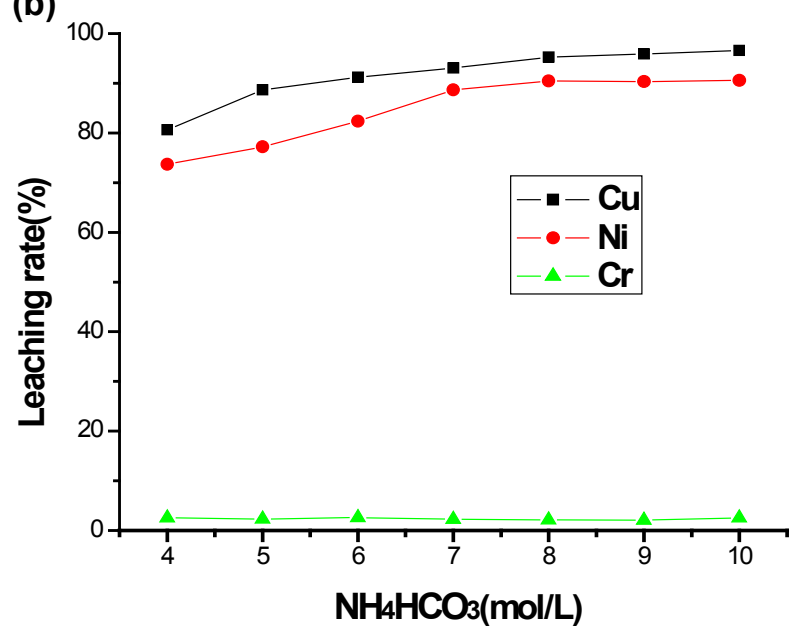

(d)

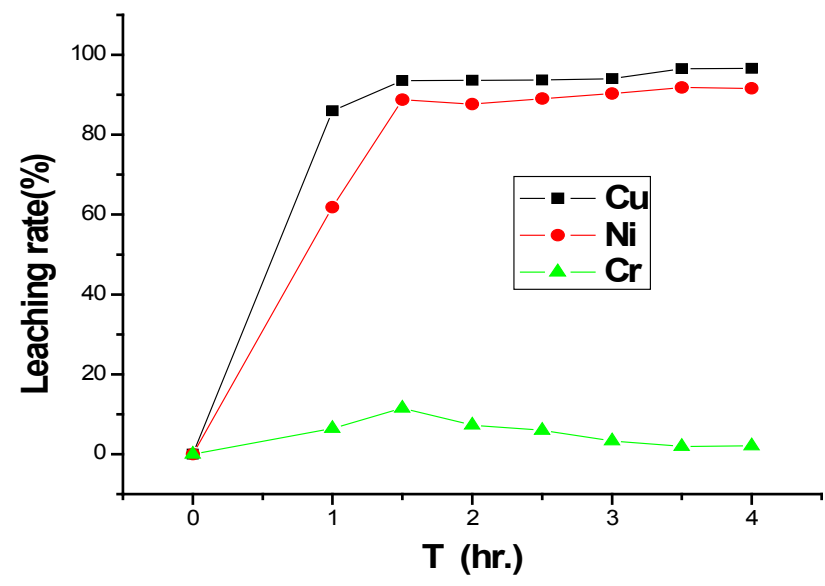

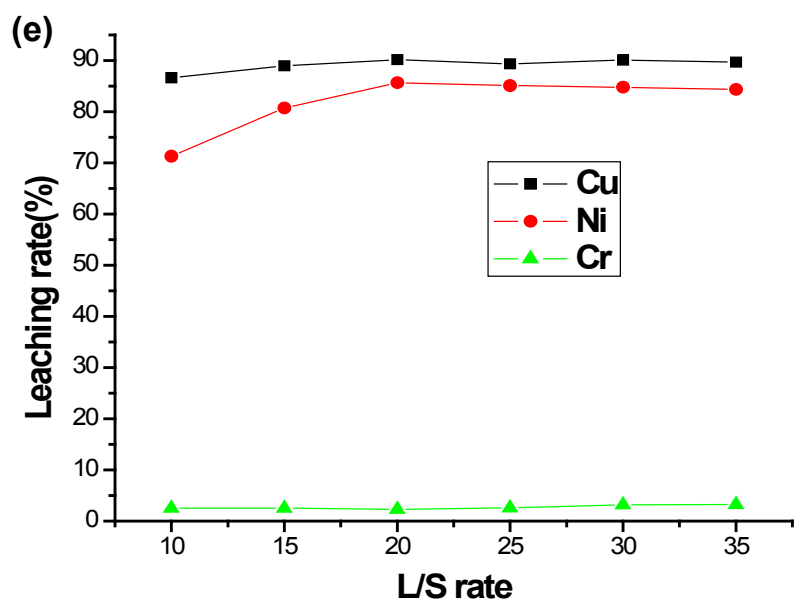

Figure 1: Effects of the factors on the leaching rate of $\mathrm{Cu}, \mathrm{Ni}$ and $\mathrm{Cr}$. (a) Effect of concentration of $\mathrm{NH}_{3}$; (b) Effect of concentration of $\mathrm{NH}_{4} \mathrm{HCO}_{3}$; (c) Effect of temperature; (d) Effect of leaching time; (e) Effect of Liquid/Solid rate. 
spectrometry (AAS method, Z-5000AA device). The main physicalchemical characteristics of the sludge are presented in Table 1.

Optimizing condition of ammonium leaching for multi-metal electroplating sludge: To separate $\mathrm{Cu}$ and $\mathrm{Ni}$ from the other metals ( $\mathrm{Cr}$ and $\mathrm{Fe}$ et al.) and eliminate the effect of existing ions, the multimetal electroplating sludge was leached with alkaline ammonium solution. Ammonia leaching can make metal ions and ammonia molecular to form a stable conjugate ion with $\mathrm{Me}\left(\mathrm{NH}_{3}\right)_{\mathrm{n}}{ }^{\mathrm{z}+}$ into the solution to separate $\mathrm{Cu}^{2+}$ and $\mathrm{Ni}^{2+}$ ions from the other impurities ions which are insoluble or cannot react with ammonia. The advantages of the leaching are the efficiency of the selective dissolving $\mathrm{Cu}$ and $\mathrm{Ni}$ and other insoluble metals (such as $\mathrm{Fe}, \mathrm{Cr}$ etc.) exist mostly in the leaching residue. By the ammonia leaching, a valuable metal ions solution with low impurity content and less consumption of leaching agent can be obtained from the multi-metal electroplating sludge. Between the same kinds of metals, the complex of high coordination number is generally more stable than that of low coordination number at the high concentration of ammonia. As long as high concentration of ammonia exists, the highest allocation of ammonia ligand ions are the vast majority of the existence in solution, then the low coordination number of ions could be neglected. The chemical process of ammonia leaching system for division of each divalent metal is as follows:

$$
\begin{aligned}
& \mathrm{Ni}(\mathrm{OH})_{2}+5 \mathrm{NH}_{3}+\mathrm{NH}_{4} \mathrm{HCO}_{3} \rightarrow \mathrm{Ni}\left(\mathrm{NH}_{3}\right)_{6}{ }^{2+} \mathrm{CO}_{3}{ }^{2-}+2 \mathrm{H}_{2} \mathrm{O} \\
& \mathrm{Cu}(\mathrm{OH})_{2}+3 \mathrm{NH}_{3}+\mathrm{NH}_{4} \mathrm{HCO}_{3} \rightarrow \mathrm{Cu}\left(\mathrm{NH}_{3}\right)_{4}{ }^{2+} \mathrm{CO}_{3}{ }^{2-}+2 \mathrm{H}_{2} \mathrm{O} \\
& 2 \mathrm{Cr}(\mathrm{OH})_{3}+9 \mathrm{NH}_{3}+3 \mathrm{NH}_{4} \mathrm{HCO}_{3} \rightarrow\left[\mathrm{Cr}\left(\mathrm{NH}_{3}\right)_{6}{ }^{3+}\right]_{2}\left(\mathrm{CO}_{3}{ }^{2-}\right)_{3}+6 \mathrm{H}_{2} \mathrm{O} \\
& \mathrm{Cr}\left(\mathrm{NH}_{3}\right)_{6}{ }^{3+}+2 \mathrm{H}_{2} \mathrm{O} \rightarrow \mathrm{CrO}(\mathrm{OH})+3 \mathrm{NH}_{4}{ }^{+}+3 \mathrm{NH}_{3}
\end{aligned}
$$

In addition, the study suggests that the activity state $\mathrm{Cr}\left(\mathrm{NH}_{3}\right)_{6}{ }^{3+}$ of $\mathrm{Cr}$ can speed up the oxidizing hydrolysis into hydroxyl passivation state $\mathrm{CrO}(\mathrm{OH})$ in the ammonia leaching process by adding a catalyst $\mathrm{AI}(\mathrm{OH})_{3}$, and thereby inhibits the leaching of $\mathrm{Cr}$ to achieve a better separation efficiency with $\mathrm{Cu}$ and $\mathrm{Ni}$.

A series oftests for ammoniumleaching of multi-metal electroplating sludge were carried out in order to optimize the conditions which contain $\mathrm{NH}_{3}$ concentration, $\mathrm{NH}_{4} \mathrm{HCO}_{3}$ concentration, the reactive temperature and time, the liquid-solid ratio(L/S) and catalyst and so on. The results are shown in Figure 1.

Figure 1(a) and Figure 1(b) suggest that the leaching rates of $\mathrm{Cu}$ and $\mathrm{Ni}$ are increasing gradually with the increasing concentration of $\mathrm{NH}_{3}$ and $\mathrm{NH}_{4} \mathrm{HCO}_{3}$, which owing to the quickly reaction between more ammonium molecular and metals. However, the rates increase slowly when the concentration of $\mathrm{NH}_{3}$ and $\mathrm{NH}_{4} \mathrm{HCO}_{3}$ are more than $8 \mathrm{~mol} / \mathrm{L}$. The effect of temperature to leaching rates of $\mathrm{Cu}$ and $\mathrm{Ni}$ are greater than that of the others Figure 1(c). With the quickly enhancement of temperature, leaching rates of $\mathrm{Cu}$ and $\mathrm{Ni}$ are increasing gradually, and the maximum leaching rates of $\mathrm{Cu}$ and $\mathrm{Ni}$ achieve within $2 \mathrm{hrs}$ at the $75^{\circ} \mathrm{C}$ Figure $1(\mathrm{~d})$. The ratio of solid to liquid affects scarcely to $\mathrm{Cu}$, and a few to $\mathrm{Ni}$ between 10 and 35 Figure $1(\mathrm{e})$. The leaching rate of $\mathrm{Cr}$ is below to $8 \%$ for all experiments, which suggests that $\mathrm{Cu}^{2+}$ and $\mathrm{Ni}^{2+}$ ions can be separated effectively from $\mathrm{Cr}^{2+}$ ion.

Through multi-group conditions of single factor ammonia leaching experiments for $\mathrm{NH}_{3}-\mathrm{NH}_{4} \mathrm{HCO}_{3}$ leaching system, optimal leaching conditions of multi-metal electroplating sludge are as follows: temperature at $75^{\circ} \mathrm{C}$, the time $\mathrm{t}=3.5 \mathrm{hrs}, \mathrm{NH}_{3}$ concentration of 8 $\mathrm{mol} / \mathrm{L}, \mathrm{NH}_{4} \mathrm{HCO}_{3}$ concentration of $5 \mathrm{~mol} / \mathrm{L}$, liquid-solid ratio $\mathrm{L} / \mathrm{S}=20$, catalyst of $0.25 \mathrm{~g} / \mathrm{L}$, and the characteristics of the ammonium leaching solution of the sludge under the optimizing condition are shown in Table 2 .
It was clear indicated that the metal ions of $\mathrm{Ni}$ and $\mathrm{Cu}$ has been separated from $\mathrm{Cr}$ and $\mathrm{Fe}$, and the impurity affect was eliminated. But about $90 \mathrm{~g} / \mathrm{L} \mathrm{NH}_{4} \mathrm{OH}$ and $45 \mathrm{~g} / \mathrm{L} \mathrm{NH}_{4} \mathrm{HCO}_{3}$ would remain in the leaching liquor.

\section{Co-extracting of $\mathrm{Cu}$ and $\mathrm{Ni}$ from ammonia-leaching aqueous}

With the ammonium leaching aqueous containing $\mathrm{Cu}$ and $\mathrm{Ni}$, the effects of single factor on extraction capacity of $\mathrm{Cu}^{2+}$ and $\mathrm{Ni}^{2+}$ ions were studied. It can be learned that $\mathrm{pH}, \mathrm{N} 902$ concentration in organic phase and the contact time have intensive influence on the rate of metal extraction, but the influence of temperature is less obvious. Extraction temperature can be controlled at $20-30^{\circ} \mathrm{C}$, that is, at room temperature. However, the actual ammonia leaching aqueous is complicated, and the various influence factors on the extraction are not isolated, that is, extraction is affected by the above-mentioned factors, as well as

\begin{tabular}{|l|l|l|l|l|l|}
\hline \multirow{2}{*}{$\begin{array}{l}\text { Leaching } \\
\text { Test }\end{array}$} & \multicolumn{5}{|l}{ Leaching metal ions $\left(\mathrm{g} . \mathrm{L}^{-1}\right)(\%)$} \\
\hline 1 & $\mathrm{Cu}$ & $\mathrm{Ni}$ & $\mathrm{Cr}$ & $\mathrm{Fe}$ & {$[\mathrm{Cu}+\mathrm{Ni}] /[\mathrm{Cr}+\mathrm{Fe}]$} \\
\hline 2 & $2.260(96.23)^{\mathrm{b}}$ & $3.383(91.76)$ & $0.015(3.86)$ & $0.063(1.56)$ & 73.6 \\
\hline 3 & $2.233(95.22)$ & $3.275(89.65)$ & $0.013(3.35)$ & $0.045(1.15)$ & 94.9 \\
\hline average & $2.252(96.03)$ & $3.335(91.12)$ & $0.014(3.68)$ & $0.054(1.43)$ & 82.2 \\
\hline
\end{tabular}

aLeaching conditions: $t=3.5 \mathrm{~h}$, L/S ratio $=20: 1$; stirring speed $=100 \mathrm{rpm}, \mathrm{T}=75^{\circ} \mathrm{C}$ bValues in brackets give the percentage of dissolution for each metal species

Table 2: Result of comprehensive test conditions of ammonia-leaching ${ }^{\text {a }}$.

\begin{tabular}{|l|l|l|l|l|l|l|}
\hline $\begin{array}{l}\text { Sequence } \\
\text { number }\end{array}$ & $\begin{array}{l}\mathrm{pH} \\
\text { /A }\end{array}$ & $\begin{array}{l}\text { Phase } \\
\text { ratio(O/A) } \\
\text { /B }\end{array}$ & $\begin{array}{l}\text { N902 } \\
\text { conc.(\%) } \\
\text { /C }\end{array}$ & $\begin{array}{l}\text { Time } \\
\text { (min.) } \\
\text { /D }\end{array}$ & \begin{tabular}{l} 
Inspection targets \\
\cline { 5 - 6 } \\
Cu extraction \\
rate(\%)
\end{tabular} & $\begin{array}{l}\text { Ni extraction } \\
\text { rate(\%) }\end{array}$ \\
\hline 1 & 8.5 & $1: 2$ & 10 & 2 & 72.6 & 39.7 \\
\hline 2 & 8.5 & $1: 1$ & 20 & 4 & 98.6 & 97.1 \\
\hline 3 & 8.5 & $2: 1$ & 30 & 6 & 95.2 & 92.7 \\
\hline 4 & 9.0 & $1: 2$ & 20 & 6 & 98.3 & 96.4 \\
\hline 5 & 9.0 & $1: 1$ & 30 & 2 & 95.6 & 83.4 \\
\hline 6 & 9.0 & $2: 1$ & 10 & 4 & 94.4 & 90.9 \\
\hline 7 & 9.5 & $1: 2$ & 30 & 4 & 98.7 & 95.3 \\
\hline 8 & 9.5 & $1: 1$ & 10 & 6 & 93.2 & 89.4 \\
\hline 9 & 9.5 & $2: 1$ & 20 & 2 & 91.7 & 81.7 \\
\hline
\end{tabular}

Table 3: The results of $L_{9}\left(3^{4}\right)$ intersect experiment of $\mathrm{Cu}$ and Ni extraction.

\begin{tabular}{|l|l|l|l|l|}
\hline \multicolumn{5}{|c|}{ Range of copper extraction rate } \\
\hline $\mathrm{K}_{1}$ & 266.4 & 269.6 & 260.2 & 259.9 \\
\hline $\mathrm{K}_{2}$ & 288.3 & 287.4 & 290.6 & 291.7 \\
\hline $\mathrm{K}_{3}$ & 285.6 & 283.3 & 289.5 & 286.7 \\
\hline $\mathrm{K}_{1}$ & 88.8 & 89.9 & 86.7 & 86.6 \\
\hline $\mathrm{K}_{2}$ & 96.1 & 95.8 & 96.9 & 97.2 \\
\hline $\mathrm{K}_{3}$ & 95.2 & 94.4 & 96.5 & 95.6 \\
\hline $\mathrm{R}$ & 7.3 & 5.9 & 10.2 & 10.6 \\
\hline Optimal decision & $\mathrm{A}_{2}$ & $\mathrm{~B}_{2}$ & $\mathrm{C}_{2}$ & $\mathrm{D}_{2}$ \\
\hline
\end{tabular}

Table 4: Analysis of range of copper extraction rate.

\begin{tabular}{|l|l|l|l|l|}
\hline \multicolumn{5}{|c|}{ Range of nickel extraction rate } \\
\hline $\mathrm{K}_{1}$ & 229.5 & 231.4 & 220 & 204.8 \\
\hline $\mathrm{K}_{2}$ & 270.7 & 269.9 & 275.2 & 283.3 \\
\hline $\mathrm{K}_{3}$ & 266.4 & 265.3 & 271.4 & 278.5 \\
\hline $\mathrm{K}_{1}$ & 76.5 & 77.1 & 73.3 & 68.3 \\
\hline $\mathrm{K}_{2}$ & 90.2 & 90.0 & 91.7 & 94.4 \\
\hline $\mathrm{K}_{3}$ & 88.8 & 88.4 & 90.5 & 92.8 \\
\hline $\mathrm{R}$ & 13.7 & 12.9 & 18.4 & 26.1 \\
\hline Optimal decision & $\mathrm{A}_{2}$ & $\mathrm{~B}_{2}$ & $\mathrm{C}_{2}$ & $\mathrm{D}_{2}$ \\
\hline
\end{tabular}

Table 5: Analysis of range of nickel extraction rate. 
the interference of impurity ions. In order to further understand the effect of factors mentioned above on the co-extraction of $\mathrm{Cu}$ and $\mathrm{Ni}$, an orthogonal experimental design was used to explore these factors on extraction equilibrium and selectivity.

For the actual ammonia leaching liquid, a set of four factors and
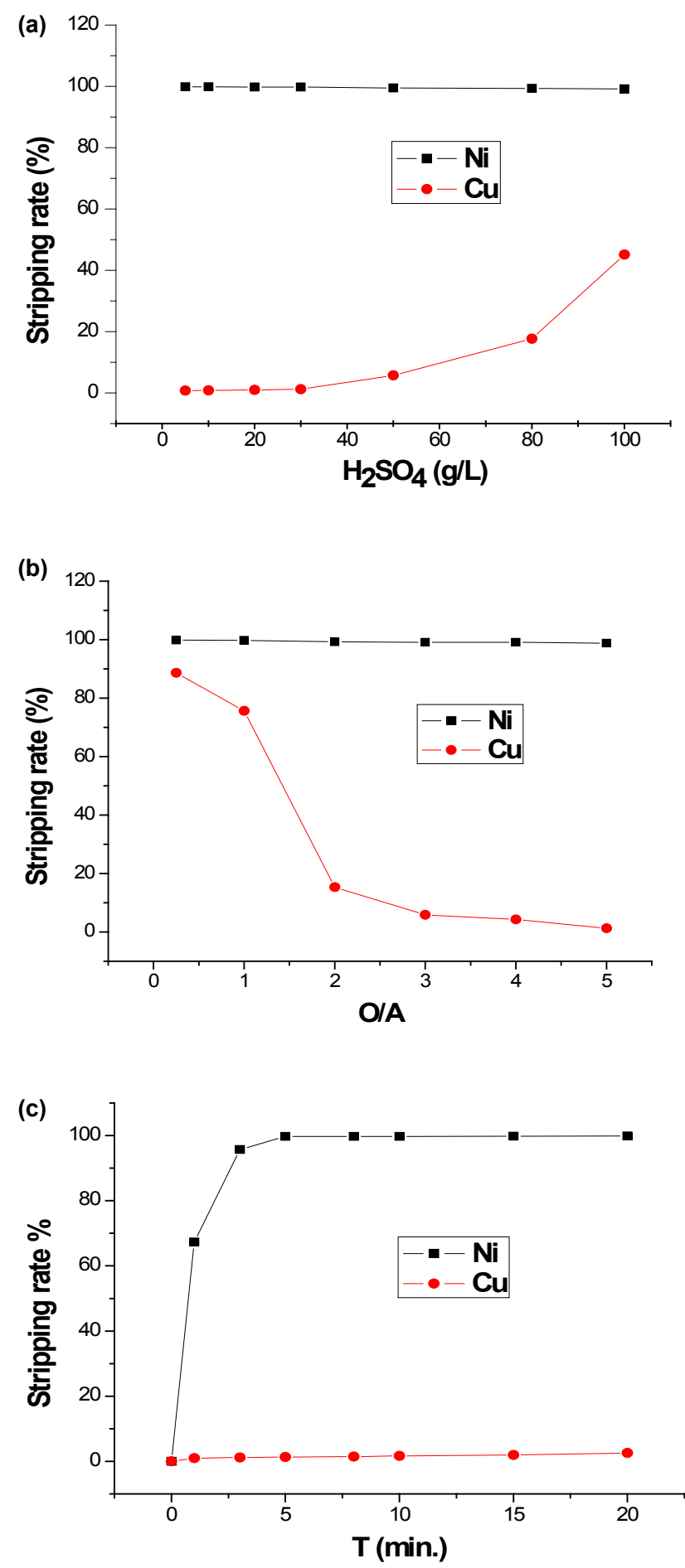

Figure 2: Effects of the factors on $\mathrm{Ni}$ selective stripping. (a) Effect of concentration of $\mathrm{H}_{2} \mathrm{SO}_{4}$; (b) Effect of O/A rate; (c) Effect of contacting time. (a)

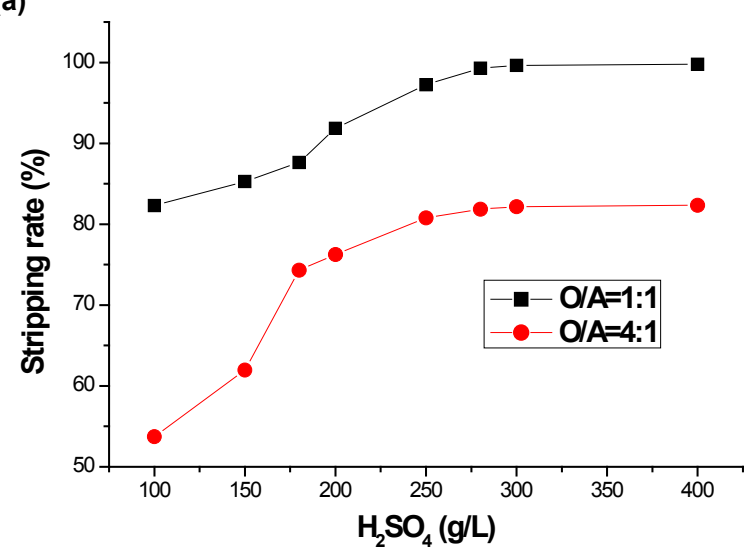

(b)
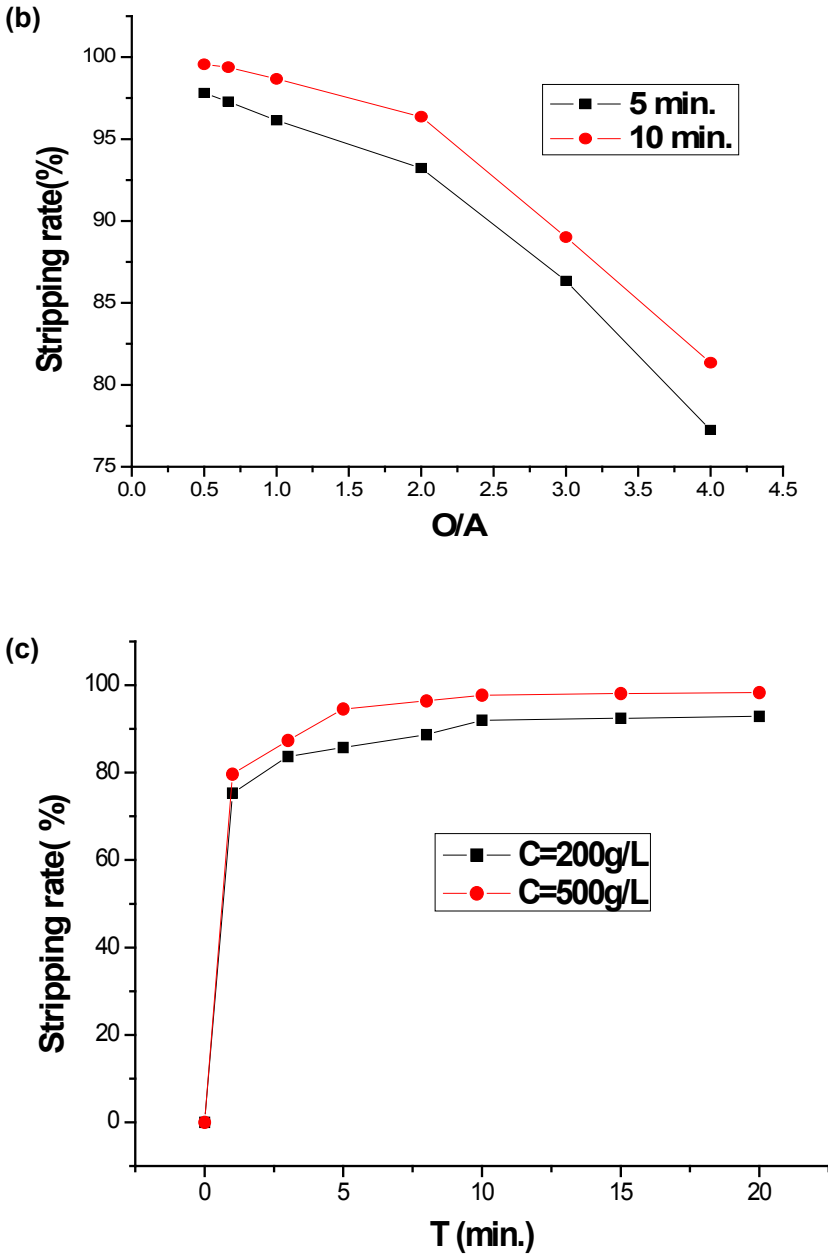

Figure 3: Effects of the factors on Cu stripping. (a) Effect of concentration of $\mathrm{H}_{2} \mathrm{SO}_{4}$; (b) Effect of O/A rate; (c) Effect of contacting time.

three levels $\mathrm{L}_{9}\left(3^{4}\right)$ orthogonal test was designed to select $\mathrm{pH}$ value, initial concentration of extractant, phase ratio (Organic/Aqueous) and the contact time. The results of orthogonal experiment are shown in Table 3 .

According to Table 3, the results of the analysis of experimental 
data are shown in Table 4, 5. From these tables, it can be seen that the initial concentration of $\mathrm{N} 902$ and the $\mathrm{O} / \mathrm{A}$ play a very important role in the extraction rate of $\mathrm{Cu}$ and $\mathrm{Ni}$. The oscillation time also affects it to some extent, but the effect of $\mathrm{pH}$ value is relatively small.

From the analysis on extraction rate of $\mathrm{Cu}$ and $\mathrm{Ni}$ above, it makes clear that the optimal conditions of the $\mathrm{Cu}^{2+}$ and $\mathrm{Ni}^{2+}$ ions co-exacting are the same for $A_{2} B_{2} C_{2} D_{2}$. Under the optimal conditions $\left(A_{2} B_{2} C_{2} D_{2}\right)$, several sets of multi-stage extraction test were conducted, and the results are shown in Table 6 . The level of $\mathrm{Cu}$ and $\mathrm{Ni}$ extraction rate are both more than $96 \%$.

\section{Ammonia removal from the loaded organic phase}

After extracting $\mathrm{Cu}$ and $\mathrm{Ni}$ by $\mathrm{N} 902$ from the ammonia solution, a small amount of ammonia with $\mathrm{Cu}$ and $\mathrm{Ni}$ together came into the organic phase due to ammonia with the stripping agent $\left(\mathrm{H}_{2} \mathrm{SO}_{4}\right)$ to form ammonium sulfate, even to form $\mathrm{NiSO}_{4} \cdot\left(\mathrm{NH}_{4}\right)_{2} \mathrm{SO}_{4} \cdot 6 \mathrm{H}_{2} \mathrm{O}$ complex $\mathrm{Ni}$ salt in the Ni stripping solution, which had an impact on follow-up treatment. Therefore, in order to reduce the consumption of sulfuric acid, it was necessary to remove ammonia from organic phase after the extraction of $\mathrm{Ni}$ and before the stripping process. Based on the existing literature [11], the distilled water was selected to remove ammonium agent. The test showed that the elution effect of ammonia would take more than $10 \mathrm{~min}$, but it slowed down the phase separation, under the condition of $\mathrm{O} / \mathrm{A}=5 / 1$, mixing time $5 \mathrm{~min}$. After washing the loaded organic phase, the rate of ammonia removal can be as high as $98 \%$, and the loss of $\mathrm{Cu}$ and $\mathrm{Ni}$ be ignored.

\section{Ni selectively stripping and recovery from the loaded organic phase}

Literature [12] and experiments show that $\mathrm{Ni}$ and $\mathrm{Cu}$ can be separate recovery by selectively stripping from the loaded organic phase because of the complex instability of Ni with the N902 under condition of low acid.

The effect of sulfuric acid on Ni selectively stripping: The effect result of sulfuric acid on Ni selectively stripping is shown in Figure 2 (a). It suggests that the sulfuric acid concentration ranges from $5 \mathrm{~g} / \mathrm{L}$ to $100 \mathrm{~g} / \mathrm{L}$ should be used to obtain reasonably sufficient Ni stripping in a single stage $(\sim 100 \%)$, so that nearly complete stripping is possible. When the sulfuric acid concentration is $30 \mathrm{~g} / \mathrm{L}$, better separation efficiency can be achieved for $\mathrm{Ni}$ and $\mathrm{Cu}$ which stripping rates are 99.77 $\%$ and $1.23 \%$, respectively.

However, with the increasing concentration of sulfuric acid, $\mathrm{Cu}$ stripping rate is getting higher and higher. When the sulfuric acid concentration is $50 \mathrm{~g} / \mathrm{L}$, the $\mathrm{Cu}$ stripping rate is $5.68 \%$, and when the sulfuric acid concentration up to $100 \mathrm{~g} / \mathrm{L}$, the $\mathrm{Cu}$ stripping rate has reached $45.12 \%$. It is not benefit for the separation of $\mathrm{Ni}$ and $\mathrm{Cu}$. Therefore, sulfuric acid concentration of $30 \mathrm{~g} / \mathrm{L}$ is the optimal concentration of stripping agent.

The effect of $\mathrm{O} / \mathrm{A}$ and contact time on Ni selectively stripping: Compared with sulfuric acid, ratio of $\mathrm{O} / \mathrm{A}$ does less effect on $\mathrm{Ni}$ stripping. Figure 2(b) shows that reasonably sufficient Ni stripping in a single stage $(\sim 100 \%)$ can be achieved in the range of $1-5$ of O/A. With the increase of $\mathrm{O} / \mathrm{A}$, the back-extraction rate of $\mathrm{Cu}$ decreases sharply, while the back-extraction rate of $\mathrm{Ni}$ is relatively stable. With the $5 / 1$ of $\mathrm{O} / \mathrm{A}$, the $\mathrm{Cu}$ stripping rate decrease by $1.27 \%$ and the Ni backextraction rate is $98.83 \%$, which means $\mathrm{Cu}-\mathrm{Ni}$ separation is effective.

Figure 2(c) indicates that with the increase of contact time, the back-extraction rate of $\mathrm{Ni}$ changes sharply, while the back-extraction rate of $\mathrm{Cu}$ is relatively stable, less than $2 \%$. Within 5 min of contact time, the satisfied $\mathrm{Ni}$ stripping rate can be achieved. $\mathrm{Cu}-\mathrm{Ni}$ separation is effective.

After the Ni back-extraction experiment, the optimal stripping conditions of $\mathrm{Ni}$ are as follows: temperature at $30 \pm 2^{\circ} \mathrm{C}$, stripping agent for the sulfuric acid concentration of $30 \mathrm{~g} / \mathrm{L}, \mathrm{O} / \mathrm{A}=5: 1$, contact time of $5 \mathrm{~min}$. From the experiment, we can find that more than $99 \%$ of $\mathrm{Ni}$ stripping rate can be achieved by the two-stage counter-current stripping, concentration of $\mathrm{Ni}$ is $15.95 \mathrm{~g} / \mathrm{L}$ in stripping solution, concentration of $\mathrm{Cu}$ is less than $0.03 \mathrm{~g} / \mathrm{L}$ and $\mathrm{Cu}$ is not striped.

\section{$\mathrm{Cu}$ stripping from the $\mathrm{Ni}$-free loaded organic phase}

The Ni-free loaded organic phase was used for carrying out $\mathrm{Cu}$ stripping study. Using the loaded organic phase containing $2.26 \mathrm{~g} / \mathrm{L}$ $\mathrm{Cu}$ and $0.002 \mathrm{~g} / \mathrm{L} \mathrm{Ni}$ and sulfuric acid as stripping agent, single stage experiments were designed, and the other conditions were shown as follows: the deferent phase ratios of 1:1 to $4: 1$ of O/A, the concentration of sulfuric acid of $100-400 \mathrm{~g} / \mathrm{L}$, temperature at $30 \pm 2^{\circ} \mathrm{C}$, contact time from 1 to $15 \mathrm{~min}$. The stripping efficiency of $\mathrm{Cu}$ is in the range of 50 $\%$ to $99 \%$ Figure 3. The optimal stripping conditions of $\mathrm{Cu}$ are as follows: temperature at $30 \pm 2^{\circ} \mathrm{C}$, stripping agent for the sulfuric acid concentration of $250 \mathrm{~g} / \mathrm{L}, \mathrm{O} / \mathrm{A}=1: 1$, contact time of $8 \mathrm{~min}$. From the experiments, we can find that more than $99 \%$ of $\mathrm{Cu}$ stripping rate can be achieved by the three-stage counter-current stripping under the optimal stripping conditions of $\mathrm{Cu}$. The concentrations of $\mathrm{Cu}$ in stripping solution and in organic phase are $2.25 \mathrm{~g} / \mathrm{L}$ and less than 0.05 $\mathrm{g} / \mathrm{L}$, respectively.

\section{Recovery of $\mathrm{Cu}$ and $\mathrm{Ni}$ products}

After stripping process, the stripping solution was heated, evaporated and crystallized. $\mathrm{Cu}$ was recovered as $\mathrm{CuSO}_{4} \cdot 5 \mathrm{H}_{2} \mathrm{O}$ purity blue crystal product ( $99.3 \%$ in purity). Ni was recovered as $\mathrm{NiSO}_{4} \cdot 6 \mathrm{H}_{2} \mathrm{O}$ green crystal product ( $98.4 \%$ in purity).

\section{Conclusions}

Process parameters were optimized for the separation and recovery of $\mathrm{Ni}$ and $\mathrm{Cu}$ from ammoniac leaching liquor obtained by ammoniac leaching of the multi-metal electroplating sludge. $\mathrm{Ni}$ and $\mathrm{Cu}$ were quantitatively co-extracted in two counter-current stages under the conditions of $1: 1$ of O/A, a 20 vol. \% N902 solution in mainly aliphatic kerosene, contact time of $4 \mathrm{~min}$ and temperature at $30 \pm 2{ }^{\circ} \mathrm{C}$. The percentage of extracting was $99.9 \%$ both for $\mathrm{Cu}$ and $\mathrm{Ni}$. The ammonia in the loaded organic phase was removed using a single stage scrubbing

\begin{tabular}{|c|c|c|c|c|c|c|c|c|}
\hline \multirow{3}{*}{ Sequence number } & \multicolumn{4}{|c|}{ Copper extraction } & \multicolumn{4}{|c|}{ Nickel extraction } \\
\hline & \multicolumn{2}{|l|}{ One-stage } & \multicolumn{2}{|l|}{ Two-stage } & \multicolumn{2}{|l|}{ One-stage } & \multicolumn{2}{|l|}{ Two-stage } \\
\hline & $\begin{array}{l}\mathrm{Cu}^{2+} \text { extra. } \\
\text { rate (\%) }\end{array}$ & $\begin{array}{l}\mathrm{Cu}^{2+} \text { conc. in } \\
\text { aqueous }(\mathrm{mg} / \mathrm{L})\end{array}$ & $\begin{array}{l}\mathrm{Cu}^{2+} \text { extra. } \\
\text { rate (\%) }\end{array}$ & $\begin{array}{l}\mathrm{Cu}^{2+} \text { conc. in } \\
\text { aqueous }(\mathrm{mg} / \mathrm{L})\end{array}$ & $\begin{array}{l}\mathrm{Ni}^{2+} \text { extra. } \\
\text { rate (\%) }\end{array}$ & $\begin{array}{l}\mathrm{Ni}^{2+} \text { conc.in } \\
\text { aqueous }(\mathrm{mg} / \mathrm{L})\end{array}$ & $\begin{array}{l}\mathrm{Ni}^{2+} \text { extra. } \\
\text { rate (\%) }\end{array}$ & $\begin{array}{l}\mathrm{Ni}^{2+} \text { conc. in } \\
\text { aqueous }(\mathrm{mg} / \mathrm{L})\end{array}$ \\
\hline 1 & 97.8 & 51.26 & $>99.9$ & 0.18 & 97.3 & 89.37 & $>99.9$ & 0.3 \\
\hline 2 & 98.2 & 41.94 & $>99.9$ & 0.20 & 96.8 & 105.92 & $>99.9$ & 0.4 \\
\hline 3 & 98.6 & 32.62 & $>99.9$ & 0.15 & 97.2 & 92.68 & $>99.9$ & 0.3 \\
\hline
\end{tabular}

Table 6: The results of multi-grade extraction of co-extraction. 
operation with water. Selective Ni stripping was achieved in a two-stage counter-current stripping at $\mathrm{O} / \mathrm{A}=5 / 1$, using the sulfuric acid of 30 $\mathrm{g} / \mathrm{L}$ and contacting time of $5 \mathrm{~min}$. The Ni stripping efficiency was 99.0 $\%$. $\mathrm{Cu}$ was stripped from the $\mathrm{Ni}$-free organic phase with the sulfuric acid of $250 \mathrm{~g} / \mathrm{L}$ in three stages at $\mathrm{O} / \mathrm{A}=1 / 1$, contact time of $8 \mathrm{~min}$. The organic containing was recycled in the system.

As far as we know, there is no any report about co-extract $\mathrm{Cu}$ (II) and Ni (II) from the ammoniac-carbonate leaching liquor of the multi-metal electroplating sludge, and almost no reports about the two-stage leaching metal ions from electroplating sludge. The results of this study suggest that this technology of recovery $\mathrm{Cu}$ and $\mathrm{Ni}$ metals from electroplating sludge can be used as a suitable reutilized method of heavy metals. The technology to dispose plating sludge not only can avoid the serious problems plating sludge caused to environment, but also can get great potential profits by reusing valuable heavy metals in plating sludge. In addition, the authors believe that the work presented in this paper will prove practically useful information for design of more efficient electroplating sludge treatment processes for metal recovery. Anyway, further work at a pilot-plant level is now in progress in order to confirm the promising results already achieved.

\section{Acknowledgement}

This paper is based on the work supported by the Bureau of Science and Technology Guangdong Province, China under the project entitled "Heavy Metal Resources Recycling Technology from the industry solid waste material”. Authors are thankful to the Ming Run Electroplating plant, Guangdong, Foushan City, China to supply the experimental sample.

\section{References}

1. Shi TH, Zou SJ, Chen J, Huang R, Wang ZC (2008) Research advance of the hydrometallurgical recovery of copper and nickel from electroplating sludge. $J$ Chin J Environ Eng 12: 35-41.
2. Shi TH, Wang ZC, Liu Y, Jia SG, Du CM (2009) Removal of hexavalent chromium from aqueous solutions by D301, D314 and D354 anion-exchange resins. J Hazard Mater 161: 900-906.

3. Kondo H, Fujita T, Kuchar D, Fukuta T, Matsuda H, et al. (2006) Separation of metal sulfides from plating wastewater containing $\mathrm{Cu}, \mathrm{Zn}$ and $\mathrm{Ni}$ by selective sulfuration with hydrogen sulfide. J Japa Hyomengijutsu 57: 901-906.

4. Silva JE, Paiva AP, Soares D, Labrincha A, Castro F (2005) Solvent extraction applied to the recovery of heavy metals from galvanic sludge. J Hazard Mater 120: 113-118.

5. Agarwal JC, Beecher N, Hubred GL, Natwig DL, Skarbo RR (1976) Meta separation by fluid ion exchange in the processing of ocean nodules. Paper presented at AIME Ann Meeting Las Vegas NV, Feb.

6. Agarwal JC, Barner HE, Beecher N, Davies DS, Kust RN (1979) Kennecott Process for recovery of copper, nickel, cobalt and molybdenum from ocean nodules. J Min Eng 31: 1704-1707.

7. Agarwal JC, Beecher N, Hubred GL, Natwig DL, Skarbo RR (1976) A new FIX on metal recovery from sea nodules. J Min Eng 177: 74-78.

8. Pandey BD, Kumar V, Bagchi D, Akerkar DD (1989) Extraction of nickel and copper from the ammoniacal leach solutions of sea nodules by LIX64N. J Ind Eng Chem Res 28: 1664-1669.

9. Rhoads SC, Nilsen DN, Siemens RE (1977) Solvent extraction of nickel, cobalt and copper from laterite-ammoniacal leach liquors. Proceedings of Proc. Internat Solv Extra Conf ISEC 77 Toronto, Canada, CIM Specl.

10. Sandhibigraha A, Bhaskara Sarma PVR (1997) Co-extraction and selective stripping of copper and nickel using LIX87QN. J Hydrometal 45: 211-219.

11. Wang CY (2002) The extraction and recovery of copper nickel and cobalt extraction from the Ammoniacal leaching solution. J Chin J Non-ferrous metals 54: $23-26$.

12. Parija C, Bhaskara Sarma PVR (2000) Separation of nickel and copper from ammoniacal solutions through co-extraction and selective stripping using LIX84 as the extractant. J Hydrometal 54: 195-204. 